\title{
РЕЧЕВЫЕ ПРОВОКАЦИИ В ПОВСЕДНЕВНОМ ИНТЕРНЕТ-ВЗАИМОДЕЙСТВИИ: ВАРИАНТЫ РЕАЛИЗАЦИИ И РАЗВИТИЕ ДИАЛОГА
}

\section{SPEECH PROVOCATIONS IN EVERYDAY INTERNET INTERACTION: VARIANTS OF REALIZATION AND DIALOGUE DEVELOPMENT}

\section{Afinogenova}

Summary: This research continues series of studies associated with illocutionary mechanism of dialogue development and turned to study speech provocations as a destabilizing form of interlocutors' communication initiative in process of Internet interaction. We analyzed discussions of information messages about COVID-19 vaccination on various Internet sites. The study showed that interlocutors' replicas realizing speech provocations dominated in Internet discussions. 17 categories of provocative intentions were revealed. Intentions aimed at referential object «Interlocutor» had the response more often among them. Several variants of dialogue development at appearance of speech provocations were described, its structure was characterized.

Keywords: everyday Internet interaction, illocutionary mechanism of dialogue development, interlocutors' communication initiative, speech provocations, provocative intentions, intent-analysis.
$\Pi$ роблема речевых провокаций получает особую актуальность в современном информационном обществе и активно разрабатывается учеными [7, 8, 9, 10, 11, 17, 21, 22 и др.]. Так, В.Н. Степанов использует термин «провоцирование» для описания взаимосвязи реплик в диалоге, полагая, что инициирующая реплика определенным образом провоцирует ответную реплику. Автор считает, что «провокационная речь, или речевая провокация, изображает и передает определенное психологическое состояние для его собеседника и как бы «заряжает» его, а цель этого - вызвать желаемое внутреннее состояние, возбудить в нем коммуникативную активность, основанную на желании соответствовать предъявляемым собеседником коммуникативным требованиям» [16, с.161]. В.Н. Степанов полагает, что речевая провокация может иметь различную эмоциональную окраску, в том время как А.А. Штеба, В.О. Кузнецов, И.М. Дзялошинский, Р.В. Жолудь отмечают, что ее важным признаком является негативный характер последствий для вовлеченного в провокацию адресата $[7,11,21]$.

В социальных медиа данный феномен может трансформироваться в троллинг, который связан с прояв-

\author{
Афиногенова Виктория Алексеевна \\ К.nсх.н., н.С., ФГБУН Институт психологии РАН (Москва) \\ AfinogenovaVA@ipran.ru
}

Аннотация: Исследование продолжает серию работ, посвященных изучению иллокутивного механизма развития диалога, и обращено к изучению речевых провокаций как дестабилизирующей формы проявления коммуникативной инициативы в процессе интернет-взаимодействия. Материалом для исследования стали обсуждения информационных сообщений о вакцинации от КОВИД-19 на различных интернет-площадках. Показано, что в интернетобсуждениях преобладают реплики коммуникантов, реализующих речевые провокации. Обнаружено 17 категорий провокативных интенций, среди которых чаще обнаруживают отклик интенции, направленные на референциальный объект «Собеседник». Описано несколько вариантов развития взаимодействия при появлении речевых провокаций, охарактеризована его структура.

Ключевые слова: повседневное интернет-взаимодействие, иллокутивный механизм развития диалога, коммуникативная инициатива собеседников, речевые провокации, провокативные интенции, интент-анализ.

лением вербальной агрессии и травлей отдельных пользователей $[1,6,12,20,23$ и др.]. Под троллингом в социальных сетях подразумевается написание провокационных сообщений с целью вызвать флейм и конфликты между участниками, а значит - дестабилизировать сетевое общение [1]. Успешная троллинг-атака изменяет тональность дискуссии, которая превращается в место спора (нередко - с включением нецензурной лексики) и зарождения конфликта [6]. Явление троллинга может быть рассмотрено как форма агрессивного социального воздействия в рамках дискурсивного пространства интернета $[12,15]$.

В нашем исследовании предполагается обращение к изучению речевых провокаций как одной из форм проявления коммуникативной инициативы. Вслед за О.С. Иссерс мы определяем речевую провокацию как коммуникативный сбой, организованный говорящим для достижения определенных целей, который побуждает партнера к таким речевым реакциям, которые могут повлечь за собой нежелательные для него последствия [10]. Автор относит этот феномен к речевым стратегиям (наряду со стратегией критики, самопрезентации и т.п.), 
которые понимает как «комплекс речевых действий, направленных на достижение коммуникативной цели» [9, с. 104]. О.С. Иссерс отмечает, что речевая стратегия обладает гибкостью: она может быть реализована через различные речевые тактики, выбор которых определяется коммуникативными целями говорящего. Конкретная речевая тактика реализуется в коммуникативных (речевых) ходах. Они связывают реплику говорящего и реплику слушающего по принципу иллокутивного вынуждения. Реплики собеседников, в свою очередь, содержат актуальные для них интенции, которые служат реализации той или иной речевой тактики [2, 3, 4, 5, 14 и др.].

Как протекает диалог после появления речевой провокации? Какое интенциональное состояние вызывает такая дестабилизация взаимодействия? Какие формы принимает речевая провокация в Интернете? На эти и другие вопросы предстоит ответить в рамках исследования.

Цель настоящего исследования - изучение речевых провокаций в процессе интернет-взаимодействия.

Гипотезы исследования: 1. Комментарии коммуникантов, реализующих речевые провокации, содержат одну или несколько интенций провокативного характера. 2. Комментарии коммуникантов, реализующих речевые провокации, всегда получают ответный отклик партнеров. 3. Появление речевых провокаций изменяет текущую линию взаимодействия.

\section{Методика}

Участники исследования. 109 человек (по данным в открытых интернет-источниках, 71 мужчина, 38 женщин).

Материал исследования. 4 информационных сообщения о вакцинации от КОВИД-19 и их обсуждение (215 комментариев, $\bar{M}=54, \min =22, \max =83$ ) в новостной ленте (Яндекс.Дзен, zen.yandex.ru), в личном блоге ЖЖ (nemihail.livejournal.com). Отбирались популярные (имеющие более 1000 просмотров, по данным в открытых интернет-источниках) сообщения указанной тематики, получившие более 20 комментариев, которые были опубликованы в январе-феврале 2021 г.

В качестве основного метода оценки психологического содержания речи выступал метод интент-анализа [14], который позволяет реконструировать стоящие за речью интенции субъектов общения и выявлять элементы интенционального содержания, сопряженные с текущим взаимодействием, коммуникативными тактиками, риторическими приемами и др. При квалификации интенций учитывались языковые и речевые маркеры, данные о цели коммуникантов, их статусно-ролевых позициях и пр., вытекающие из анализа контекста, а также ответные реакции собеседника, обнаруживающие его понимание сказанного.

\section{Результаты и их обсужАение}

Проведенный интент-анализ позволяет обнаружить 17 категорий провокативных интенций, присущих диалогическому интернет-взаимодействию. Опираясь на представление О.С. Иссерс о речевой провокации [8, 10], мы относим к провокативным интенции, побуждающие партнера к таким речевым действиям (коммуникативным ходам'), которые могут повлечь за собой нежелательные для него последствия. Критерий отнесения интенции к провокативным - ее негативный перлокутивный эффект ${ }^{2}$, который выражается, в том числе, в дестабилизации эмоционального состояния.

Как видно из таблицы 1, наиболее частотными (> 20 случаев реализации) среди них оказываются такие категории, как «унизить» («Не ври много, от вранья глаза косыми станут!», «Интеллект у тебя не более чем на $\left.2 \times 2^{3} »\right)$, «выразить иронию» («Выжить последние деньги хорошо сказал!»), «выразить сарказм» («Сейчас в тренде супер пупер мега лекарство - апрели - арпели - тьфуты - фуфрловир»), «оскорбить» («Вы бараны смотрите зомби ящик и носите маски», «Одни нытики кругом»), «выразить возмущение» («Да что вам так завидно, что людям по 10000 дали?!», «Как можно завидовать несчастному человеку хотя бы и с грин картой?!»).

Обнаружено, что провокативные интенции реализованы в 171 комментарии (80\% общего числа комментариев), при этом в 44\% таких реплик обнаружено 2 и более подобных интенций, что усиливает эффект провоцирования. Представленные факты подтверждают первую эмпирическую гипотезу.

Как показывает сравнительный анализ, в повседневном оффлайн-взаимодействии $[3,4,13]$ только $14 \%$ высказываний содержат провокативные интенции $(\mathrm{n}=215)$. Иными словами, провокативный характер диалога можно считать отличительной особенностью повседневного интернет-взаимодействия.

Дальнейшее исследование показало, что лишь 24\%

1 Под коммуникативным ходом понимается единство реплики говорящего и слушающего, которые организованы по принципу иллокутивного вынуждения.

2 Перлокутивный эффект - эффект, который достигается в результате реализации высказывания с определенным намерением (иллокутивной целью).

3 Здесь и далее в речевых примерах сохранены авторская орфография и пунктуация. 
Таблица 1.

Представленность провокативных интенций в интернет-взаимодействии

\begin{tabular}{|c|l|l|c|}
\hline$№$ п/п & Категории провокативных интенций & \multicolumn{1}{|c|}{ Определение категориич } & Частота реализации \\
\hline 1 & унизить & Оскорбить чью-то гордость, чувство собственного достоинства & 57 \\
\hline 2 & выразить иронию & Выразить тонкую, скрытую насмешку & 53 \\
\hline 3 & выразить сарказм & Выразить язвительную насмешку, злую иронию & 37 \\
\hline 4 & оскорбить & Крайне обидеть, причинить моральный ущерб & 30 \\
\hline 5 & выразить возмущение & Выразить сильное раздражение, негодование & 24 \\
\hline 6 & критиковать & Указывать на недостатки кого-либо / чего-либо & 17 \\
\hline 7 & обвинить & Счесть виновным, укорить кого-либо & 16 \\
\hline 8 & побудить к действию & Склонить к какому-либо действию & 15 \\
\hline 9 & выразить недовольство & Выразить раздраженность, отрицательное отношение & 14 \\
\hline 10 & обесценить & Лишить ценности & 13 \\
\hline 11 & выразить пренебрежение & Выразить высокомерное, лишенное уважения отношение к кому- \\
\hline 12 & возразить & зиему-либо & 7 \\
\hline 13 & осудить & Вырить о своем несогласии & 5 \\
\hline 14 & выразить презрение & $\begin{array}{l}\text { Выразить подчеркнутое безразличие, подчеркнуть подлость и } \\
\text { ничтожность кого-либо / чего-либо }\end{array}$ & 2 \\
\hline 15 & упрекнуть & Выразить кому-либо неодобрение, неудовольствие & 3 \\
\hline 16 & намекнуть & Иметь ввиду кого-либо / что-либо, говоря намеками & 299 \\
\hline 17 & убедить & Заставить поверить чему-либо, уговором склонить к чему-либо & 2 \\
\hline
\end{tabular}

реализованных провокативных интенций получают отклик коммуникантов ( $\mathrm{n=299):} \mathrm{собеседники} \mathrm{при} \mathrm{желании}$ могут оставить обращенные к ним интенции, в том числе, провокативные, без ответа и не развивать потенциально конфликтный диалог. Это факт указывает на значительную гибкость повседневного интернет-взаимодействия. Чаще (> 5 раз) обнаруживают реакцию такие категории, как «унизить» $(n=19)$, «оскорбить» $(n=12)$, «выразить сарказм» $(n=7)$, «критиковать» $(n=6)$, «обвинить» $(n=6)$, «выразить иронию» $(\mathrm{n}=5)$.

Как показывает проведенный анализ, чаще получают отклик провокативные интенции, направленные на референциальный объект «Собеседник» $(66,7 \%$ случаев отклика на провокативные интенции, $\mathrm{n}=72$ ) («Как вы докатились до такой медицины? Ведь триллионы нефтедолларов! А всё бабло по офшорам разошлось с вашего-быдлоэлекторат--попустительства» - «Стесняюсь спросить, почему вы так переживаете за «быдлоэлекторат»?»): партнер стремится ответить на адресованную ему речевую провокацию, что указывает на диалогичность повседневного интернет-взаимодействия.
Реже обнаруживают отклик провокативные интенции, направленные на объекты:

- «Российская власть» (12,5\%) («Одно не пойму если путинская вакцина такая эффективная, то почему российские морги переполнены, мест в больнице нет и даже насквозь лживая российская статистика констатирует рост заболеваемости» - «Путинская вакцина настолько эффективная, что ее до сих пор перепроверяют не в силах поверить в такую ох *** эфрфективность!»),

— «Сообщество» (9,7\%) («Я не врач, но это не мешает мне видеть весь бред, который сейчас несется из высших сфер, и помогает мне в этом - РАЗУМ, которым, увы, очень многие не научились пользоваться! Главное, не терять здравый смысл никогда!» - «Про ЗДРАВЫЙ СМЫСЛ - это Вы более чем точно. Я предлагаю вспомнить старинную немецкую пословичу «Потеряешь БДИТЕЛЬНОСТЬ (в смысле ЗДРАВЫЙ СМЫСЛ) - nотеряешь ДЕВСТВЕННОСТЬ»),

— «Россияне» (8,3\%) («Пока сытый сохнет худой сдохнет, как поговаривали на России крепостные предки крепостных» - «Со своим ответом ты по-

4 Для определения категорий использованы Толковый словарь русского языка с включением сведений о происхождении слов (под ред. Н.Ю. Шведовой), Толковый словарь русского языка: в 4 томах (под ред. Д.Н. Ушакова). 
хож на залупу сумасшедшего хохла»);

- крайне редко - на объект «Государственные структуры (МЧС, ДЗ и др.)» (2,8\%) («Если в России нет системы здравоохранения, то и лечить то некому как правило. Препараты против конкретно 19-го не найдены, поэтому лечат, как обычный грипn. Нет чёткой стратегии, как при СССР» - «Какой вы враг! В России как раз сохранена система»).

Bсе эти интенции адресованы неперсонализированным объектам в отличие от объекта «Собеседник», который предусматривает обращение к конкретным участникам диалога. Обнаруженные в подобных случаях отклики свидетельствуют о том, что коммуникант предполагает свою принадлежность к обозначенным структурам и воспринимает себя как адресата интенций.

Выделено несколько вариантов развития текущей линии взаимодействия при появлении провокативных реплик ${ }^{5}(n=208)$. В одних случаях $(44,2 \%)$ провокативные реплики обнаруживают ответный отклик коммуниканта:

А: Какой пугающий бред гуляет по сети... просто мрак. От так называемых «врачей». Надеюсь, воздастся таким «врачам» по их заслугам однажды. $\mathbf{H u}$ мозгов, ни совести!

Б: Среди каких ужасных людей мы живем, проклинающих врачей! прям как проклятье звучит! Ужас какой! Сколько злобы в ответ на предостережение! Да воздастся таким клянущим им по заслугам и не однажды!!!

В других случаях $(22,1 \%)$ партнеры игнорируют провокацию, обращая внимание на другие интенции собеседника:

А: A при чем тут вообще люди и их поведение?! Полностью уничтожить экономику было распоряжением ВОЗа. Так же как и постоянное запугивание из СМИ.

Б: ВОЗ тоже лишь исполнитель, заказчик- Всемирный банк.

В третьих (33,7\%) - коммуниканты оставляют провокативный комментарий без ответа, продолжая текущую линию разговора:

A: Это у вас есть серьезнейший повод задуматься о вашем психическом здоровье, ну а по поводу воспитания можете не задумываться, в связи с его полным отсутствием. Но главное, о чем стоит сожалеть, так это об отсутствии здравого смысла.
Б: Один опытный доктор, профессор медицинских наук и всякое такое, сказал мне следующую фразу почти дословно: «Ковид не убивает, убивает страх перед ковидом».

Два последних варианта демонстрируют коммуникативную неудачу провокатора: его намерение не получает соответствующего отклика. Полученные данные указывают на то, что вторая эмпирическая гипотеза подтверждается частично.

Итак, реализованная речевая провокация в части случаев $(\mathrm{n}=92)$ приводит к изменению речевого поведения собеседника, а значит и изменению текущей линии взаимодействия (что подтверждает третью эмпирическую гипотезу). Рассмотрим подробнее эти ситуации.

Реакция партнера на провокацию может осуществляться в форме подчинения или, наоборот, сопротивления. Обнаружено лишь несколько случаев подчинения $(\mathrm{n}=6)$, которое реализуется в интенциях «выразить согласие», «солидаризоваться» («Не забивайте голову дурными мыслями. Усе умрём» - «Это так»): зачастую коммуниканты имеют свою позицию и редко поддаются вынуждению провокатора.

Наиболее многочисленны случаи сопротивления речевой провокации $(\mathrm{n}=86)$ : коммуниканты противостоят намерению провокатора изменить их речевое поведение. Можно выделить так называемое конструктивное сопротивление, которое обнаруживает возможность компромисса и может служить прекращению конфронтации собеседников. Оно реализуется в таких интенциональных категориях, как «напомнить», «посоветовать», «выразить иное мнение», «защитить (себя / другого)» и др., однако выявляется не часто, лишь в $15 \%$ случаев («То то наши (прим. - МЧС РФ) пока не съездили к ним (прим. - в Италию) и не помыли там все смертность у них зашкаливала!» - «На севере «зашкаливала», а на бедном юге была на минимуме! И потом вы же наверняка помните высказывание Дизраэли: «есть ложь, наглая ложь и статистика!»»).

Более типичны случаи так называемого деструктивного сопротивления (85\% случаев), которое реализуется во взаимной провокации и, напротив, приводит к обострению конфронтации. При этом реализуются такие интенции, как «выразить сарказм», «унизить», «обесценить», «оскорбить» и др. («Надо мозгами быть не очень богатым, чтобы покупать квартиру в таком клоповнике в 30 этажей. Чем такие люди думают, интересно?» «Мы живем в этом доме с 1983 года! И рядом построил Олигарх Доронин 50 этажный дом, и здесь все продано. Мы то в Советское время получали бесплатно. Так что

5 Провокативная реплика - высказывание, содержащее одну или несколько интенций провокативного характера. 
по себе не мерьте!»; «А вы, я так понимаю, не россиянское быдло, а дочь Рокфеллера. И за вами обязательно пришлют самолёт. И это хорошо, умрёте в специализированной клинике» - «Вы мне завидуете? Получайте green card и умрите по людски а не зассанном матрасе в подсобке»). Собеседники обнаруживают активное сопротивление партнеру-провокатору и невозможность мириться со сказанным, стремление защитить свою позицию, что приводит к эскалации спора.

Структуру интернет-взаимодействия в условиях речевых провокаций можно характеризовать как разветвленную узловую: в «узле» находится комментарий, получивший множество откликов собеседников. Один из этих откликов может стать началом новой линии диалога, который таким образом значительно разветвляется.

\section{Выводы}

Проведенный интент-анализ повседневного интернет-взаимодействия выявил 17 категорий провокативных интенций, наиболее частотными среди которых оказались «унизить», «выразить иронию», «выразить сарказм», «оскорбить», «выразить возмущение».

В интернет-обсуждениях преобладают реплики коммуникантов, в которых реализованы одна или несколько провокативных интенций, что указывает на провокативный характер повседневного интернет-взаимодействия.

Лишь 24\% выраженных провокативных интенций получают отклик собеседников, что указывает на значительную гибкость интернет-взаимодействия и возможность продолжать диалог без нежелательной конфронтации. При этом чаще обнаруживают отклик интенции, направленные на референциальный объект «Собеседник», что свидетельствует о диалогичности такого взаимодействия.

Выделено несколько вариантов развития текущей линии взаимодействия при появлении провокативных реплик. В одних случаях такие реплики обнаруживают ответный отклик коммуниканта, реализуемый в форме подчинения или сопротивления (конструктивного / деструктивного); в других случаях намерения провокатора не получают соответствующего отклика, обнаруживается его коммуникативная неудача.

Структура повседневного интернет-взаимодействия в условиях речевых провокаций характеризуется как разветвленная узловая: в «узле» находится комментарий, получивший множество откликов, один из которых может стать началом новой линии диалога и привести к его разветвлению.

\section{ЛИТЕРАТУРА}

1. Акулич М.М. Троллинг в социальных сетях: возникновение и развитие // Вестник РУДН. Серия Социология. 2012. №3. С.30-37.

2. Афиногенова В.А. Функционирование механизма иллокутивного вынуждения в речевом взаимодействии собеседников // Вестник МгоУ (электронный журнал). 2019. №3.

3. Афиногенова В.А. Иллокутивное вынуждение и коммуникативная инициатива в речевом взаимодействии собеседников // Психологические исследования: Выпуск 10. / Под ред. А.Л. Журавлева, Е.А. Сергиенко, Н.Е. Харламенковой. - М.: Изд-во «Институт психологии РАН», 2020. С.30-39.

4. Афиногенова В.А. Последовательное развертывание диалога и коммуникативная инициатива собеседников (на материале повседневного дискурса взрослых и детей) // Современная наука: актуальные проблемы теории и практики. Серия: Познание. 2020. №9. С.18-21.

5. Афиногенова В.А. Иллокутивный механизм развития диалога: результаты исследования // Жизнь языка в культуре и социуме - 8. Материалы международной научной конференции. Москва, 28 - 29 мая 2021 г. / Ред. коллегия: Е.Ф. Тарасов (отв. ред.), Н.В. Уфимцева, В.П. Синячкин, Е.С. Ощепкова, О.В. Балясникова, Д.В. Маховиков. - М., 2021. С. 199-200.

6. Воронин А.Н., Ковалева Ю.В. Изменение субъектности сетевого сообщества в процессе троллинга // Институт психологии Российской академии наук. Социальная и экономическая психология. 2019. Т. 4. №3 (15). С.25-61.

7. Дзялошинский И.М., Жолудь Р.В. Провокация в системе коммуникационных технологий // Коммуникации. Медиа. Дизайн. 2017. Т.2. №2. С.62-81.

8. Иссерс 0.С. Дискурсивные практики нашего времени. - М.: Ленанд, 2021. 272 с.

9. Иссерс 0.С. Коммуникативные стратегии и тактики русской речи. - М.: Ленанд, 2017. 308 с.

10. Иссерс 0.С. Стратегия речевой провокации в публичном диалоге // Русский язык в научном освещении. 2009. №2 (18). С.92-104.

11. Кузнецов В.0. «Провокация» как экспертное понятие в судебной лингвистической экспертизе // Теория и практика судебной экспертизы. 2020. Т.15. №3. C.6-18.

12. Немыка А.А., Ушаков А.А. Дискурсивное пространство текста: троллинг как элемент некооперативной речевой стратегии современной интернет-коммуникации // Вестник РУДН. Серия Вопросы образования: языки и специальность. 2012. № 4. С. 68-71.

13. Павлова Н.Д., Афиногенова В.А., Гребенщикова Т.А. Речевое взаимодействие собеседников в неформальном повседневном дискурсе: интенциональный аспект // Психологический журнал. 2017. Т.38. №5. С.41-54.

14. Павлова Н.Д., Гребенщикова Т.А. Интент-анализ: основания, процедура, опыт использования. - М.: Изд-во «Институт психологии РАН», 2017.151 с.

15. Психология дискурса: проблема детерминации, воздействия, безопасности / Под ред. А.Л. Журавлева, Н.Д. Павловой, И.А. Зачесовой. - М.: Изд-во 
«Институт психологии РАН», 2016.315 с.

16. Степанов В.Н. Провокационный вопрос с точки зрения прагмалингвистики // Московский лингвистический журнал. 2003. Т.6. №2. С.157-180.

17. Степанов В.Н. Провоцирование в социальной и массовой коммуникации: монография. - СПб.: Роза мира, 2008. 268 с.

18. Толковый словарь русского языка: в 4 томах / Под ред. Д.Н. Ушакова. - М.: АСТ, 2009.848 с.

19. Толковый словарь русского языка с включением сведений о происхождении слов / Отв. ред. Н.Ю. Шведова. - М.: Издательский центр «Азбуковник», 2011. 1175 c.

20. Фетисова Т.А. Агрессивное поведение в интернет-коммуникации // Культурология. 2018. №4 (87). С.185-197.

21. Штеба А.А. Лингвистические признаки провокации // Litera. 2017. №1. С. 120-128.

22. Magu R., Hossain N., Kautz H. Analizing uncivil speech provocation and implicit topics in online political news // Computers and society. 2018. preprint. 23. McCosker A. Trolling as provocation: YouTube's agonistic publics // Convergence. 2014. №20 (2). P. 201-217.

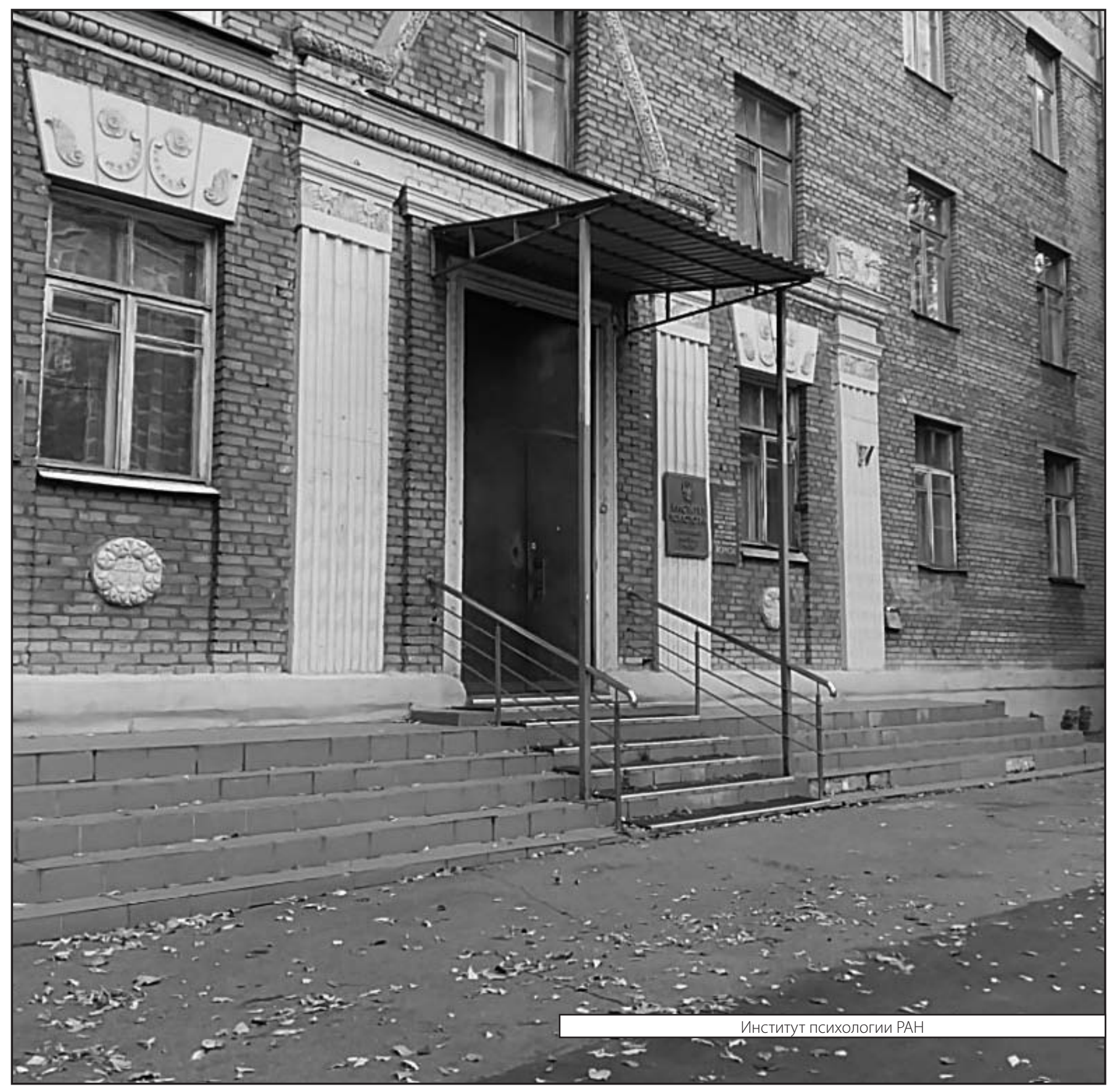

